\title{
Épocas de plantio e doses de nitrogênio e potássio na produtividade e armazenamento da cebola
}

\author{
Geraldo Milanez de Resende( ${ }^{(1)}$ e Nivaldo Duarte Costa(1)
}

(1)Embrapa Semi-Árido, Caixa Postal 23, CEP 56302-970 Petrolina, PE. E-mail: gmilanez@cpatsa.embrapa.br, ndcosta@cpatsa.embrapa.br

\begin{abstract}
Resumo - O objetivo deste trabalho foi avaliar o efeito de épocas de plantio e doses de nitrogênio e potássio sobre a produtividade e armazenamento de cebola, cultivar Texas Grano 502 PRR. Foram conduzidos dois experimentos de março a novembro de 2001, e de agosto de 2001 a março de 2002. O delineamento experimental foi de blocos ao acaso, em parcelas subdivididas com fatorial 4x3. Nas parcelas ficaram as épocas de plantio (março e agosto) e nas subparcelas o fatorial compreendendo quatro doses de $\mathrm{N}\left(0,60,120 \mathrm{e} 180 \mathrm{~kg} \mathrm{ha}^{-1}\right)$ e três doses de $\mathrm{K}_{2} \mathrm{O}\left(0,90\right.$ e $\left.180 \mathrm{~kg} \mathrm{ha}^{-1}\right)$, com três repetições. O plantio de março apresentou maior produtividade comercial $\left(66,5 \mathrm{Mg} \mathrm{ha}^{-1}\right)$ comparativamente ao de agosto $\left(41,4 \mathrm{Mg} \mathrm{ha}^{-1}\right)$. Na ausência da adubação potássica e na dose de $90 \mathrm{~kg} \mathrm{ha}^{-1}$ de $\mathrm{K}_{2} \mathrm{O}$, verificaram-se incrementos lineares na produtividade comercial de acordo com a adubação nitrogenada, enquanto na dose $180 \mathrm{~kg} \mathrm{ha}^{-1} \mathrm{de} \mathrm{K}_{2} \mathrm{O}$, a adubação nitrogenada apresentou comportamento quadrático, com ponto de mínima produtividade na dose de $23,5 \mathrm{~kg} \mathrm{ha}^{-1}$ de $\mathrm{N}$. Quanto à produtividade nãocomercial, o plantio de março alcançou 6,0 $\mathrm{Mg} \mathrm{ha}^{-1}$, enquanto o de agosto alcançou 5,4 $\mathrm{Mg} \mathrm{ha}^{-1}$. Observaram-se efeitos significativos de $\mathrm{N}$ e $\mathrm{K}$ e da interação para perda de massa de bulbos aos 40 e 80 dias após cura.
\end{abstract}

Termos para indexação: Allium cepa, adubação, conservação pós-colheita, rendimento.

\section{Nitrogen and potassium levels on the onion yield and storage with different planting times}

\begin{abstract}
The objective of this work was to evaluate the effect of different planting times and nitrogen and potassium levels on onion yield and postharvest storage, cultivar Texas Grano 502 PRR. Two trials were carried out from March to November 2001 and from August 2001 to March 2002, in Brazilian Northeast. A randomized complete block design with split-plot in a 4x3 factorial scheme was used. The plots consisted of planting dates (March and August) and the subplots of the factorial involving four levels of nitrogen $\left(0,60,120\right.$ and $\left.180 \mathrm{~kg} \mathrm{ha}^{-1}\right)$ and three levels of potassium $\left(0,90\right.$ and $\left.180 \mathrm{~kg} \mathrm{ha}^{-1} \mathrm{~K}_{2} \mathrm{O}\right)$ with three replications. The March planting showed higher commercial yield (66.5 $\left.\mathrm{Mg} \mathrm{ha}^{-1}\right)$ than August plating (41.4 $\left.\mathrm{Mg} \mathrm{ha}^{-1}\right)$. In the absence of the potassium fertilization and at the level of $90 \mathrm{~kg} \mathrm{ha}^{-1}$ of $\mathrm{K}_{2} \mathrm{O}$, linear increments were observed in the commercial yield according to nitrogen fertilization, while at $180 \mathrm{~kg} \mathrm{ha}^{-1}$ of $\mathrm{K}_{2} \mathrm{O}$, the nitrogen fertilization showed quadratic behavior, with point of minimum yield at $23.5 \mathrm{~kg} \mathrm{ha}^{-1}$. Regarding non-commercial yield (culls), the March planting obtained $6.0 \mathrm{Mg} \mathrm{ha}^{-1}$ and August 5.4 $\mathrm{Mg} \mathrm{ha}^{-1}$. Significant effects of N, K and of the interaction were observed for bulb mass loss at 40 and 80 days after cure.
\end{abstract}

Index terms: Allium cepa, fertilization, postharvest conservation, yield.

\section{Introdução}

No Brasil, a cebola ocupa o terceiro lugar em importância comercial e econômica entre as hortaliças. No Nordeste brasileiro, é predominantemente produzida no Vale do São Francisco, onde é cultivada durante o ano todo, com plantio concentrado nos meses de janeiro a março, sendo os estados de Pernambuco e Bahia os maiores produtores, com quase a totalidade da área cultivada (Souza \& Resende, 2002). O potássio e nitrogênio são os elementos mais absorvidos em termos de percentagem na matéria seca da cebola (Pôrto et al., 2007).

Quanto à capacidade de resposta a doses de N, diferentes autores relatam que o elemento contribui marcadamente para melhor produtividade da cultura. Faria et al. (1992) verificaram que o nível econômico de $\mathrm{N}$ na cultura da cebola é de $115 \mathrm{~kg} \mathrm{ha}^{-1}$. Boyhan et al. (2007) observaram que as melhores respostas quanto à produtividade foram obtidas com a dose de $263 \mathrm{~kg} \mathrm{ha}^{-1}$ de $\mathrm{N}$. 
Outros trabalhos, no entanto, não encontraram respostas positivas quando as doses de $\mathrm{N}$ variaram de 84 a $224 \mathrm{~kg} \mathrm{ha}^{-1}$ (Batal et al., 1994) e de 318 a $480 \mathrm{~kg} \mathrm{ha}^{-1}$ (Vidigal, 2000).

Apesar de a cebola extrair grande quantidade de K, respostas da cultura a esse nutriente, de maneira geral, não têm sido observadas (Filgueira, 2003), e há poucos resultados que confirmam o efeito significativo do fertilizante potássico na produtividade, embora não se conheça o seu efeito sobre a qualidade e a conservação do produto (Magalhães, 1993).

Um aumento na produtividade da cebola com a aplicação de $40 \mathrm{~kg} \mathrm{ha}^{-1}$ de $\mathrm{K}_{2} \mathrm{O}$ e ausência de resposta a doses de 80 e $160 \mathrm{~kg} \mathrm{ha}^{-1}$ é relatado por Kumar et al. (2001). Aumento no diâmetro e na massa de matéria fresca do bulbo foi relatado por Mohanty \& Das (2001) com a aplicação de $60 \mathrm{~kg} \mathrm{ha}^{-1}$ de $\mathrm{K}_{2} \mathrm{O}$, enquanto Akhtar et al. (2002) observaram aumento na produtividade até a dose de $200 \mathrm{~kg} \mathrm{ha}^{-1}$ de $\mathrm{K}_{2} \mathrm{O}$, quando em presença de adubações nitrogenadas e fosfatadas.

Singh \& Dhankhar (1991) observaram que, em bulbos armazenados sob condições ambiente, a perda de massa e a incidência de bulbos podres e brotados aumentaram com o incremento das doses de $\mathrm{N}$ ( $80 \mathrm{a} 160 \mathrm{~kg} \mathrm{ha}^{-1}$ ) e reduziram com a dose de $100 \mathrm{~kg} \mathrm{ha}^{-1}$ de $\mathrm{K}_{2} \mathrm{O}$. Doses de $80 \mathrm{~kg} \mathrm{ha}^{-1}$ de $\mathrm{N}$ mais $100 \mathrm{~kg} \mathrm{ha}^{-1}$ de $\mathrm{K}_{2} \mathrm{O}$ proporcionaram as melhores respostas em qualidade de armazenamento.

No que se refere à época de plantio, a cebola é uma cultura influenciada por condições agroclimáticas, que determinam a época de plantio de cada cultivar (Souza \& Resende, 2002). A formação de bulbos está relacionada à interação entre a temperatura e fotoperíodo. Nessa interação, o fator mais importante é o fotoperíodo, que determina os limites de adaptação das diferentes cultivares (Galmarini, 1997). Trata-se de uma espécie de dia longo e, para bulbificar, requer um número de horas com sol maior que o valor crítico da cultivar (Filgueira, 2003).

Nas condições do Submédio São Francisco, D’Oliveira et al. (1984) verificaram produtividades variando de 12,6 a $17,6 \mathrm{Mg} \mathrm{ha}^{-1}$ para diferentes épocas de plantio. As menores produtividades foram verificadas no período de maior ocorrência de temperaturas elevadas e precipitação.

O objetivo deste trabalho foi avaliar os efeitos da época de plantio e de doses de $\mathrm{N}$ e $\mathrm{K}$ na produtividade e no armazenamento de bulbos de cebola, nas condições do Vale do São Francisco.

\section{Material e Métodos}

Os experimentos foram conduzidos em condições irrigadas, de março a novembro de 2001 e de agosto de 2001 a março de 2002, no Campo Experimental de Bebedouro, da Embrapa Semi-Árido, em Petrolina, PE. O solo, classificado como Latossolo Vermelho-Amarelo distróferrico, apresentou $\mathrm{pH}$ $\left(\mathrm{H}_{2} \mathrm{O}\right), 6,2 ; \mathrm{Ca}, 2,1 \mathrm{cmol}_{\mathrm{c}} \mathrm{dm}^{-3} ; \mathrm{Mg}, 0,7 \mathrm{cmol}_{\mathrm{c}} \mathrm{dm}^{-3}$; $\mathrm{Na}, 0,01 \mathrm{cmol}_{\mathrm{c}} \mathrm{dm}^{-3} ; \mathrm{K}, 0,22 \mathrm{cmol}_{\mathrm{c}} \mathrm{dm}^{-3} ; \mathrm{Al}$, $0,00 \mathrm{cmol}_{\mathrm{c}} \mathrm{dm}^{-3} ; \mathrm{P}\left(\right.$ Mehlich 1), 9,0 $\mathrm{mg} \mathrm{dm}^{-3} \mathrm{e} \mathrm{MO}$, $6,7 \mathrm{~g} \mathrm{~kg}^{-1}$.

A adubação de plantio constou de $60 \mathrm{~kg} \mathrm{ha}^{-1} \mathrm{de}_{2} \mathrm{P}_{5}$ (superfosfato simples). As adubações nitrogenada e potássica foram aplicadas via água de irrigação, utilizando-se injetores hidráulicos de fertilizantes, de acordo com os diferentes tratamentos, com início aos cinco dias após o transplantio (DAT). Durante o experimento, foram realizadas 44 aplicações de $\mathrm{N}$ (uréia), até os 60 DAT; e 59 aplicações de K (cloreto de potássio), até os 70 DAT. Maior número de dias para adubação potássica deveu-se ao estádio fenológico da planta, em que o nutriente apresenta maior importância por ocasião da fase de bulbificação e início de maturação da cebola.

As semeaduras (cultivar Texas Grano 502 PRR) foram realizadas em 22 de março e 29 de agosto de 2001, e o transplantio foi efetuado 35 dias após. O preparo do solo constou de aração, gradagem e levantamento dos canteiros a $0,20 \mathrm{~m}$ de altura. A cultura foi mantida livre da concorrência de plantas daninhas, por meio de capinas manuais, e a irrigação (microaspersão) foi realizada diariamente, com lâminas em torno de 5 a $7 \mathrm{~mm}$, baseada na evaporação do tanque classe $\mathrm{A}$, e suspensa 20 dias antes da colheita. Os tratos fitossanitários foram realizados de acordo com as recomendações para a cultura da cebola (Souza \& Resende, 2002).

As colheitas foram realizadas quando as plantas apresentaram sinais avançados de senescência, como amarelecimento e folhas secas, com mais de $70 \%$ das plantas estaladas. A cura foi realizada ao sol por três dias, e por 12 dias à sombra, em galpão ventilado.

$\mathrm{O}$ delineamento experimental utilizado foi em blocos ao acaso, em parcelas subdivididas com fatorial $4 \times 3$. Nas parcelas, ficaram as épocas de plantio (semeaduras: março e agosto) e nas subparcelas, o fatorial compreendendo quatro doses de $\mathrm{N}\left(0,60,120 \mathrm{e} 180 \mathrm{~kg} \mathrm{ha}^{-1}\right)$ e três doses de $\mathrm{K}_{2} \mathrm{O}\left(0,90 \mathrm{e} 180 \mathrm{~kg} \mathrm{ha}^{-1}\right)$, com três repetições. A unidade experimental foi distanciada uma da outra por 
2,0 m e constituiu-se de um canteiro com oito linhas de 3,0 $\mathrm{m}$ de comprimento, em espaços de $0,15 \mathrm{~m}$, com $0,10 \mathrm{~m}$ entre plantas. Utilizou-se como área útil as seis linhas centrais, retirando-se $0,50 \mathrm{~m}$ em cada extremidade.

Foram avaliadas a produtividade comercial (bulbos perfeitos e com diâmetro transversal acima de $35 \mathrm{~mm}$ ) e não-comercial de bulbos (refugos, com diâmetro inferior a $35 \mathrm{~mm}$ ) aos 15 dias após a cura. A massa de matéria fresca de bulbo $\left(\mathrm{g} \mathrm{bulbo}^{-1}\right)$ foi determinada dividindo-se a massa de bulbos comerciais, após a cura, pelo número de bulbos.

Após o período de cura, os bulbos foram armazenados à temperatura ambiente por 80 dias. Os períodos de armazenamento dos bulbos foram de temperatura média mensal de $26,1^{\circ} \mathrm{C}$ e umidade relativa média de $57,3 \%$, referente ao plantio de março e temperatura média mensal de $26,2^{\circ} \mathrm{C}$ e umidade relativa média de $66,7 \%$, referente ao plantio de agosto. Foram realizadas pesagens aos 40 e 80 dias, e os valores foram comparados aos obtidos no final da cura (15 dias após colheita). Os valores foram transformados em percentagem de perda de massa. Os dados coletados foram submetidos à análise de variância e regressão polinomial, e as percentagens foram transformadas em $\operatorname{arcsen}(\mathrm{P} / 100)^{0,5}$, para efeito de análise.

\section{Resultados e Discussão}

Os resultados obtidos para produtividade comercial evidenciaram efeitos significativos das épocas de plantio e das interações $\mathrm{N}$ x épocas e $\mathrm{N}$ x $\mathrm{K}$, conforme a característica avaliada.

O plantio de março apresentou maior produtividade comercial $\left(66,5 \mathrm{Mg} \mathrm{ha}^{-1}\right)$ comparativamente ao de agosto (41,4 $\left.\mathrm{Mg} \mathrm{ha}^{-1}\right)$, tendo as doses de $\mathrm{N}$ aumentado linearmente a produtividade comercial nas duas épocas de plantio (Tabela 1). Os melhores resultados obtidos no plantio de março podem ser explicados pela melhor adaptação da cebola às condições de temperaturas mais amenas, que ocorrem nessa época. As temperaturas mais elevadas, que se verificam a partir de agosto, favorecem a formação de bulbos precoces e maturação mais rápida (bulbos de menor tamanho), o que reduz a produtividade (Souza \& Resende, 2002).

Verificaram-se, na ausência da adubação potássica e na dose de $90 \mathrm{~kg} \mathrm{ha}^{-1}$ de $\mathrm{K}_{2} \mathrm{O}$, incrementos lineares na produtividade comercial em função da adubação nitrogenada, enquanto na dose $180 \mathrm{~kg} \mathrm{ha}^{-1}$ de $\mathrm{K}_{2} \mathrm{O}$, a resposta à adubação nitrogenada foi quadrática, com ponto de mínima produção na dose de $23,5 \mathrm{~kg} \mathrm{ha}^{-1}$ de N (Figura 1). Respostas positivas à aplicação de N na cultura da cebola têm sido relatadas por diversos autores nas doses de $150 \mathrm{~kg} \mathrm{ha}^{-1}$ (Singh et al., 2004), $200 \mathrm{~kg} \mathrm{ha}^{-1}$ (Neeraja et al., 2001) e com $120 \mathrm{~kg} \mathrm{ha}^{-1}$ de $\mathrm{K}_{2} \mathrm{O}$ (Singh \& Verma, 2001), no entanto, sem avaliação da interação entre os nutrientes. Em interação, Singh et al. (2000) verificaram produtividades maiores com $100 \mathrm{~kg} \mathrm{ha}^{-1} \mathrm{de}$ $\mathrm{N}$ e $83 \mathrm{~kg} \mathrm{ha}^{-1}$ de $\mathrm{K}_{2} \mathrm{O}$; Lee et al. (2003) com 136 de N e $96 \mathrm{~kg} \mathrm{ha}^{-1}$ de $_{2} \mathrm{O}$, enquanto Mandira \& Khan (2003) obtiveram melhores rendimentos com $150 \mathrm{~kg} \mathrm{ha}^{-1}$ de N e $75 \mathrm{~kg} \mathrm{ha}^{-1}$ de $\mathrm{K}_{2} \mathrm{O}$. Resende et al. (1997) afirmam que há um efeito significativo e complementar na absorção de $\mathrm{N}$ e $\mathrm{K}$ em milho, e que o importante é a necessidade de um nível adequado de $\mathrm{K}$ para incrementar a produtividade com a adição de $\mathrm{N}$, fato este também evidenciado neste trabalho.

Quanto à produtividade não-comercial (refugos), o plantio de março obteve $6,0 \mathrm{Mg} \mathrm{ha}^{-1}$ e o de agosto, $5,4 \mathrm{Mg} \mathrm{ha}^{-1}$. Nas duas épocas, o aumento das doses de $\mathrm{N}$ promoveu uma redução linear na produção de refugos (Tabela 1). Quando se analisou a interação $\mathrm{N}$ versus $\mathrm{K}$, detectou-se uma redução linear gradativa da produção de bulbos considerados não-comerciais com aumento das doses de $\mathrm{N}$ e K (Figura 2). Esses

Tabela 1. Equações de regressão para produtividade comercial e não-comercial $\left(\mathrm{Mg} \mathrm{ha}^{-1}\right)$, massa de matéria fresca do bulbo ( $\mathrm{g}$ bulbo $\left.{ }^{-1}\right)$ e percentagem de perda de massa de matéria fresca aos 40 e 80 dias após a cura de bulbos de cebola, conforme as épocas de plantio, doses de potássio $(\mathrm{K})$ e nitrogênio $(\mathrm{N})$.

\begin{tabular}{|c|c|c|}
\hline Época & Equação de regressão & $\mathrm{R}^{2}$ \\
\hline & Produtividade comercial & \\
\hline Março & $\mathrm{Y}=40,2998+0,2910 * * \mathrm{~N}$ & 0,88 \\
\hline \multirow[t]{2}{*}{ Agosto } & $\mathrm{Y}=35,7788+0,0624 * * \mathrm{~N}$ & 0,85 \\
\hline & Produtividade não-comercial & \\
\hline Março & $\mathrm{Y}=9,6333-0,0400 * * \mathrm{~N}$ & 0,98 \\
\hline \multirow[t]{2}{*}{ Agosto } & $\mathrm{Y}=7,9110-0,0281 * * \mathrm{~N}$ & 0,94 \\
\hline & Massa de matéria fresca do bulbo & \\
\hline Março & $\mathrm{Y}=94,0404+0,03099 * * \mathrm{~N}$ & 0,80 \\
\hline \multirow[t]{2}{*}{ Agosto } & $\mathrm{Y}=74,4129+0,1406 \mathrm{~N}-0,000617 * * \mathrm{~N}^{2}$ & 0,80 \\
\hline & Perda de massa de matéria fresca 40 dias & \\
\hline Março & $\mathrm{Y}=23,4256-0,0150^{* *} \mathrm{~K}$ & 0,97 \\
\hline \multirow[t]{2}{*}{ Agosto } & $\mathrm{Y}=20,4453-0,0308 \mathrm{~K}+0,000218 * * \mathrm{~K}^{2}$ & 0,80 \\
\hline & Perda de massa de matéria fresca 80 dias & \\
\hline Março & $\mathrm{Y}=37,0308-0,0425 \mathrm{~K}+0,000131 * \mathrm{~K}^{2}$ & 1,00 \\
\hline Agosto & $\mathrm{Y}=27,7110-0,0351 \mathrm{~K}+0,000220 * * \mathrm{~K}^{2}$ & 1,00 \\
\hline
\end{tabular}


resultados concordam com os obtidos por May (2006), que observou reduções na quantidade de refugos com aplicação de N (115 kg ha-1 de N) e K (150 kg ha-1 de $\mathrm{K}_{2} \mathrm{O}$ ), e com os obtidos por Ghaffoor et al. (2003), que constataram menores produtividades de refugos com o aumento da adubação com NPK. Esses autores demonstraram também a capacidade de resposta da cebola às aplicações de $\mathrm{Ne} \mathrm{K}$, corroborando afirmações de Lee et al. (2003) e Mandira \& Khan (2003), que relatam que esses elementos contribuem marcadamente para melhor produtividade da cultura, sobretudo na produção de bulbos de maior tamanho.

Verificou-se maior massa de matéria fresca do bulbo no plantio de março (121,9 g por bulbo) comparativamente ao plantio de agosto, que apresentou $79,3 \mathrm{~g}$ por bulbo. No plantio de março, constatou-se efeito linear positivo das doses de $\mathrm{N} \mathrm{e}$, no de agosto, observouse efeito quadrático, com a dose de $114,0 \mathrm{~kg} \mathrm{ha}^{-1} \mathrm{de} \mathrm{N}$ como a que propiciou maior massa de matéria fresca de bulbo (Tabela 1). Na ausência da adubação potássica e na dose de $90 \mathrm{~kg} \mathrm{ha}^{-1}$, observaram-se efeitos lineares positivos da adubação nitrogenada sobre a massa de matéria fresca do bulbo. Na dose de $180 \mathrm{~kg} \mathrm{ha}^{-1}$ de $\mathrm{K}_{2} \mathrm{O}$, verificou-se efeito quadrático, com ponto de mínima massa de matéria fresca de bulbo na dose de $34,7 \mathrm{~kg} \mathrm{ha}^{-1}$ de N (Figura 3). Estes resultados estão de acordo com os obtidos para produtividade comercial. Singh et al. (2004) observaram incrementos na massa de matéria fresca do bulbo até as doses de $150 \mathrm{~kg} \mathrm{ha}^{-1}$ de $\mathrm{N}$ e $120 \mathrm{~kg} \mathrm{ha}^{-1}$ de $\mathrm{K}_{2} \mathrm{O}$. May et al. (2007) afirmaram que a aplicação de $\mathrm{N}$ é mais importante que a de $\mathrm{K}$.

No que se refere à percentagem de perda de massa de matéria fresca do bulbo aos 40 dias após cura, o

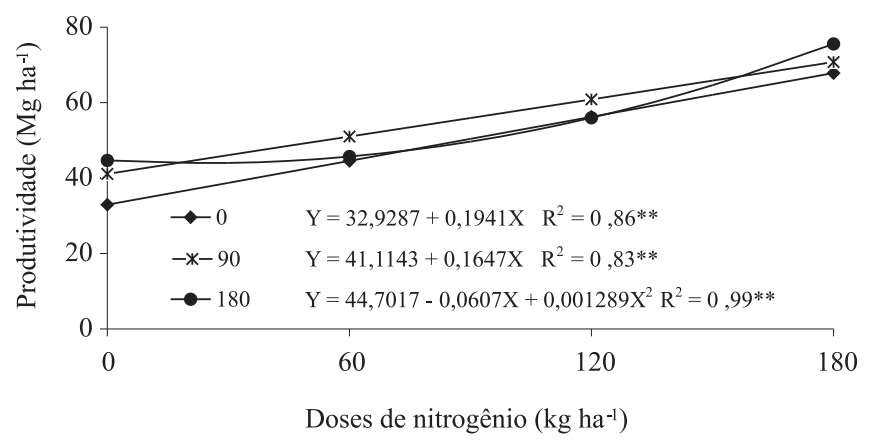

Figura 1. Produtividade comercial de bulbos de cebola de acordo com a adubação nitrogenada, nas doses 0,90 e $180 \mathrm{~kg} \mathrm{ha}^{-1}$ de $\mathrm{K}_{2} \mathrm{O}$. plantio de março obteve maiores perdas $(14,1 \%)$ que o plantio de agosto $(12,4 \%)$. Esse resultado pode ser explicado pela maior produtividade e massa de matéria fresca de bulbo (com conseqüente aumento na quantidade de água nos bulbos) obtidas em março.

Observou-se, na perda de massa de matéria fresca durante o armazenamento, uma interação significativa entre épocas de plantio e doses de K, não observada em outras características. Pelos desdobramentos da interação, constatou-se, para o plantio de março, redução linear nas perdas com o incremento das doses de $\mathrm{K} \mathrm{e}$, no plantio de agosto, efeitos quadráticos, com ponto de mínima perda na dose de $70,6 \mathrm{~kg} \mathrm{ha}^{-1}$ de $\mathrm{K}_{2} \mathrm{O}$ (Tabela 1). Não há relatos sobre resultados com cebola que venham a reforçar os obtidos neste trabalho, no entanto, eles podem ser justificados provavelmente pelo fato de o K promover maior teor

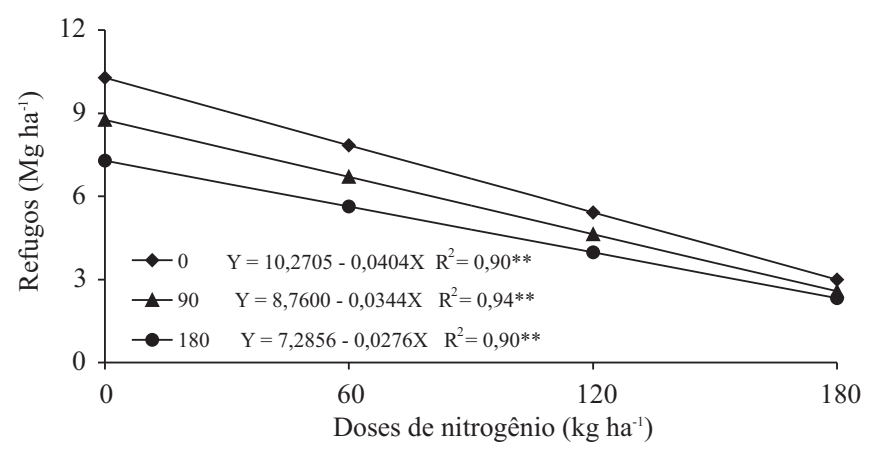

Figura 2. Produtividade não-comercial (refugos) de bulbos de cebola de acordo com a adubação nitrogenada, nas doses 0,90 e $180 \mathrm{~kg} \mathrm{ha}^{-1}$ de $\mathrm{K}_{2} \mathrm{O}$.

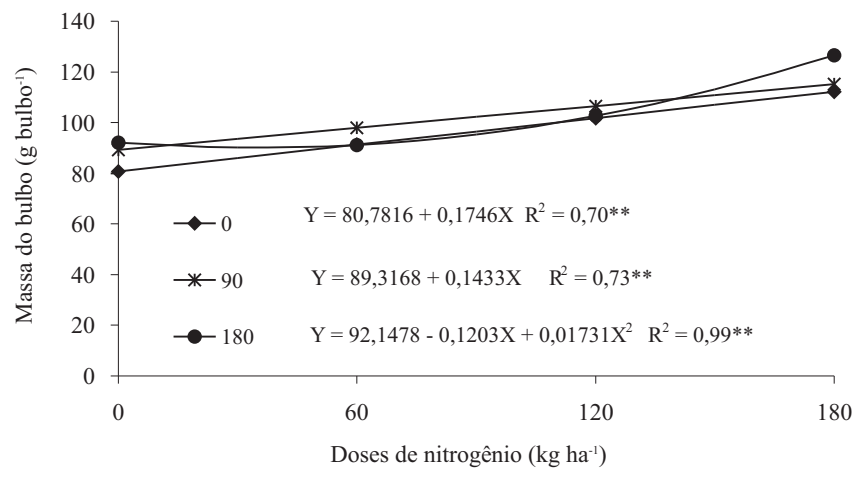

Figura 3. Massa de matéria fresca de bulbo de acordo com a adubação nitrogenada, nas doses 0,90 e $180 \mathrm{~kg} \mathrm{ha}^{-1}$ de $\mathrm{K}_{2} \mathrm{O}$. 
de sólidos solúveis (Brix) nos bulbos, com conseqüente maior teor de matéria seca, que promove melhor conservação pós-colheita. Maior teor de sólidos solúveis com a adubação potássica já foi verificado em outras hortaliças, como em tomate (Hartz et al., 1999), pimentão (Nannetti, 2001) e melancia (Cecílio Filho et al., 2004), em função de o nutriente desempenhar importante papel na translocação de fotoassimilados (Malavolta, 2006).

Verificaram-se, ainda, efeitos da interação N x K para a perda de massa de matéria fresca. Com o desdobramento da interação, verificaram-se efeitos não-significativos da adubação nitrogenada, na ausência da adubação potássica. Para as doses de 90 e $180 \mathrm{~kg} \mathrm{ha}^{-1}$ de $\mathrm{K}_{2} \mathrm{O}$, detectaram-se respostas quadráticas ao $\mathrm{N}$, nas quais se estimaram, respectivamente, as dose de 98 e $127 \mathrm{~kg} \mathrm{ha}^{-1}$ de $\mathrm{N}$ como as que promoveram as maiores percentagens de perdas de massa de bulbos comerciais (Figura 4). A qualidade e conservação de bulbos de cebola influenciada pelo $\mathrm{N}$ é também relatada por Ristimäki \& Papadopoulos (2000).

Resultados similares foram observados para perda de massa aos 80 dias após cura, quando o plantio de março apresentou maiores perdas $(32,7 \%)$ que o plantio de agosto $(21,4 \%)$. Assim como na perda de massa aos 40 dias após a cura, detectaram-se efeitos positivos da interação épocas de plantio versus doses de $\mathrm{K}$, com efeito quadrático das doses de K e pontos de mínima perda nos plantios de março e agosto com as doses de 158,6 e $162,2 \mathrm{~kg} \mathrm{ha}^{-1}$ de $\mathrm{K}_{2} \mathrm{O}$ (Tabela 1). Observaram-se, ainda, efeitos da interação $\mathrm{N}$ x K, em que, na ausência da adubação potássica, a resposta ao $\mathrm{N}$ foi quadrática, com a dose de $103,4 \mathrm{~kg} \mathrm{ha}^{-1}$ de $\mathrm{N}$, possibilitando menor perda de massa de matéria fresca de bulbo. Com relação às doses de $90 \mathrm{e}$ $180 \mathrm{~kg} \mathrm{ha}^{-1}$ de $\mathrm{K}_{2} \mathrm{O}$, constataram-se efeitos lineares das doses de $\mathrm{N}$ na redução da perda de massa (Figura 5).

Os resultados obtidos em pós-colheita são comparáveis aos encontrados por Singh \& Dhankhar (1991), que verificaram, em bulbos armazenados sob condições ambiente, que as doses de $80 \mathrm{~kg} \mathrm{ha}^{-1}$ de $\mathrm{N}$ e $100 \mathrm{~kg} \mathrm{ha}^{-1}$ de $\mathrm{K}_{2} \mathrm{O}$ tiveram as melhores respostas em qualidade de armazenamento. Hussaini et al. (2000), no entanto, não observaram efeitos do $\mathrm{N}$ até a dose de $164 \mathrm{~kg} \mathrm{ha}^{-1}, 19$ semanas após a colheita.

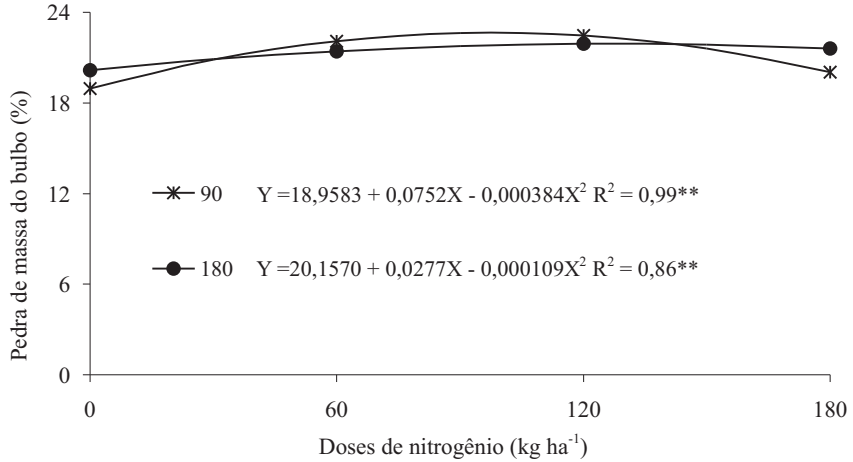

Figura 4. Perda de massa de matéria fresca de bulbo aos 40 dias após cura de acordo com a adubação nitrogenada, nas doses 90 e $180 \mathrm{~kg} \mathrm{ha}^{-1}$ de $\mathrm{K}_{2} \mathrm{O}$.

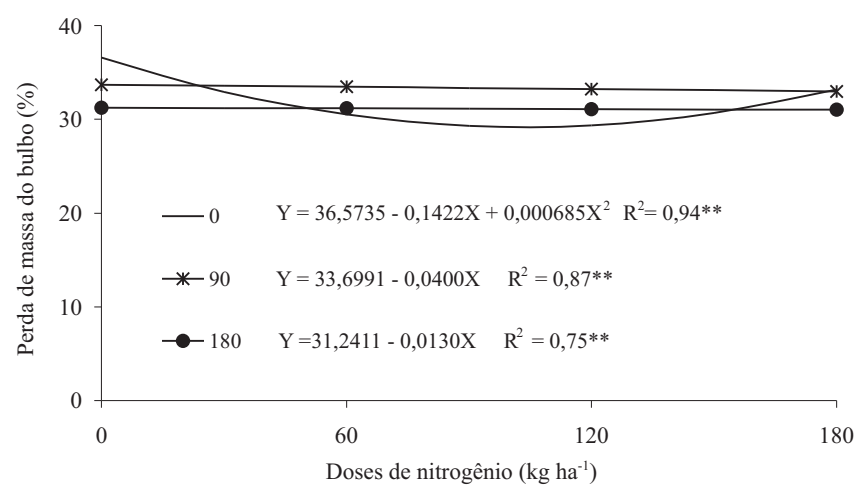

Figura 5. Perda de massa de matéria fresca de bulbo aos 80 dias após cura de acordo com a adubação nitrogenada, nas doses 0,90 e $180 \mathrm{~kg} \mathrm{ha}^{-1}$ de $\mathrm{K}_{2} \mathrm{O}$.

\section{Conclusões}

1. O plantio de março proporciona maior produtividade comercial comparativamente ao de agosto.

2. Independentemente da época de plantio, o nitrogênio, isoladamente ou em interação com o potássio, promove redução na produtividade de refugos.

3. O potássio é de grande importância na conservação pós-colheita de bulbos de cebola.

\section{Referências}

AKHTAR, M.E.; BASHIR, K.; KHAN, M.Z.; KHOKLAR, K.M. Effect of potash application on yield of different varieties of onion (Allium cepa L.). Asian Journal of Plant Science, v.1, p.324-325, 2002.

BATAL, K.M.; BONDARI, K.; GRANBERRY, D.M.; MULLINIX, B.G. Effects of source, rate, and frequency of $\mathrm{N}$ application on 
yield, marketable grades and rot incidence of sweet onion (Allium сера L. cv. Granex-33). Journal of Horticultural Science, v.69, p.1043-1051, 1994.

BOYHAN, G.E.; TORRANCE, R.L.; HILL, C.R. Effects of nitrogen, phosphorus, and potassium rates and fertilizer sources on yield and leaf nutrient status of short-day onions. HortScience, v.42, p.653660, 2007.

CECILIO FILHO, A.B.; GRANGEIRO, L.C. Qualidade de frutos de melancia sem sementes em função de fontes e doses de potássio. Ciência e Agrotecnologia, v.28, p.570-576, 2004.

D’OLIVEIRA, L.O.B.; AGUIAR, P.A.A.; ASSUNÇÃO, M.V. Competição de cultivares de cebola no Submédio São Francisco visando à produção de bulbos. Pesquisa Agropecuária Brasileira, v.19, p.193-196, 1984.

FARIA, C.M. de; PEREIRA, J.R. Fontes e níveis de nitrogênio na produtividade de cebola no Submédio São Francisco. Pesquisa Agropecuária Brasileira, v.27, p.403-407, 1992.

FILGUEIRA, F.A.R. Novo manual de olericultura: agrotecnologia moderna na produção e comercialização de hortaliças. 2.ed. Viçosa: Editora UFV, 2003. 412p.

GALMARINI, C.R. Caracteristicas botanicas y fisiologicas. In: GALMARINI, C.R. (Ed.). Manual del cultivo de la cebolla. San Juan: INTA, 1997. 128p.

GHAFFOOR, A.; JILANI, M.S.; KHALIQ, G.; WASEEM, K. Effect of different NPK levels on the growth and yield of three onion (Allium сера L.) varieties. Asian Journal of Plant Sciences, v.2, p.342-346, 2003.

HARTZ, T.K.; GIANNINI, C.; MIYAO, G.; VALENCIA, J.; CAHN, M.; MULLEN, R.; BRITTAN, K. Soil cation balance affects tomato fruit color disorders. Acta Horticulturae, v.487, p.49-55, 1999.

HUSSAINI, M.A.; AMANS, E.B.; RAMALAN, A.A. Yield, bulb size distribution, and storability of onion (Allium cepa L.) under different levels of $\mathrm{N}$ fertilization and irrigation regime. Tropical Agriculture, v.77, p.145-149, 2000.

KUMAR, A.; SINGH, R.; CHHILLAR, R.K. Influence of nitrogen and potassium application on growth, yield and nutrient uptake by onion (Allium сера). Indian Journal of Agronomy, v.46, p.742-746, 2001.

LEE, J.T.; HA, I.J.; LEE, C.J.; MOON, J.S.; CHO, Y.C. Effect of N, $\mathrm{P}_{2} \mathrm{O}_{5}$, and $\mathrm{K}_{2} \mathrm{O}$ application rates and top dressing time on growth and yield of onion (Allium cepa $\mathrm{L}$.) under spring culture in low land. Korean Journal of Horticultural Science and Technology, v.21, p.260-266, 2003.

MAGALHÃES, J.R. Nutrição e adubação da cebola. In: SIMPÓSIO SOBRE NUTRIÇÃO E ADUBAÇÃO DE HORTALIÇAS, 1990, Jaboticabal, SP. Anais. Piracicaba: Potafos, 1993. p.381-399.

MALAVOLTA, E. Manual de nutrição mineral de plantas. São Paulo: Agronômica Ceres, 2006. 638p.

MANDIRA, C.; KHAN, A.H. Effect of nitrogen and potassium on growth, yield and yield attributes of onion. New Agriculturist, v.14, p.9-11, 2003.
MAY, A. Desempenho de híbridos de cebola em função da população de plantas e fertilização nitrogenada e potássica. 2006. 142p. Tese (Doutorado) - Universidade Estadual Paulista, Jaboticabal.

MAY, A.; CECÍLIO FILHO, A.B.; PORTO, D.R.Q.; VARGAS, P.F.; BARBOSA, C.B. Produtividade de híbridos de cebola em função da população de plantas e da fertilização nitrogenada e potássica. Horticultura Brasileira, v.25, p.53-59, 2007.

MOHANTY, B.K.; DAS, J.N. Response of rabi onion cv. Nasik Red to nitrogen and potassium fertilization. Vegetable Science, v.28, p.40-42, 2001.

NANNETTI, D.C. Nitrogênio e potássio aplicados via fertirrigação na produção, nutrição e pós-colheita do pimentão. 2001. 184p. Tese (Doutorado) - Universidade Federal de Lavras, Lavras.

NEERAJA, G.; REDDY, K.M.; REDDY, M.S.; RAO, V.P. Influence of irrigation and nitrogen levels on bulb yield, nutrient uptake and nitrogen use efficiencies in rabi onion (Allium cepa). Indian Journal of Agricultural Sciences, v.7, p.109-111, 2001. PÔRTO, D.R. de Q.; CECILIO FILHO, A.B.; MAY, A.; VARGAS, P.F. Acúmulo de macronutrientes pela cultivar de cebola Superex estabelecida por semeadura direta. Ciência Rural, v.37, p.949-955, 2007.

RESENDE, G.M. de; SILVA, G.L. da; PAIVA, L.E.; DIAS, P.F.; CARVALHO, J.G. de. Resposta do milho (Zea mays L.) a doses de nitrogênio e potássio em solo da região de Lavras-MG. II. Macronutrientes na parte aérea. Ciência e Agrotecnologia, v.21, p.477-483, 1997.

RISTIMÄKI, L.M.; PAPADOPOULOS, I. Slow-release fertilizers on vegetables. Acta Horticulturae, v.511, p.125-131, 2000.

SINGH, J.; DHANKHAR, B.S. Effect of nitrogen, potash and zinc on storage loss of onion bulbs (Allium cepa L.). Vegetable Science, v.18, p.16-23, 1991.

SINGH, R.P.; JAIN, N.K.; POONIA, B.L. Response of Kharif onion to nitrogen, phosphorus and potash in eastern plains of Rajasthan. Indian Journal of Agricultural Sciences, v.70, p.871-872, 2000.

SINGH, S.; YADAV, P.K.; SINGH, S. Effect of nitrogen and potassium on growth and yield of onion (Allium cepa L.) cv. Pusa Red. Haryana Journal of Horticultural Sciences, v.33, p.308309, 2004.

SINGH, S.P.; VERMA, A.B. Response of onion (Allium cepa) to potassium application. Indian Journal of Agronomy, v.46, p.182-185, 2001.

SOUZA, R.J.; RESENDE, G.M. de. Cultura da cebola. Lavras: Ufla, 2002. 115p. (Textos Acadêmicos - Olericultura, 21).

VIDIGAL, S.M. Adubação nitrogenada de cebola irrigada cultivada no verão: projeto Jaíba, Norte e Minas Gerais. 2000. 136p. Tese (Doutorado) - Universidade Federal de Viçosa, Viçosa.

Recebido em 28 de setembro de 2007 e aprovado em 30 de janeiro de 2008 